The views expressed in this editorial are those of the author(s) and do not necessarily reflect the position of the publisher, the journal's editorial board or the Canadian College of Neuropsychopharmacology.

\title{
Legalizing marijuana
}

\author{
Marco Leyton, PhD
}

In October 2015 Canadians elected a federal government that proposes to legalize marijuana for recreational use following in the footsteps of 4 American states (Alaska, Colorado, Oregon and Washington) and the District of Columbia. Is this a good idea, and how might we decide?

\section{Risks associated with cannabis use}

As a start, cannabis use can lead to problems. ${ }^{1,2}$ Chronic users exhibit cognitive deficits, ${ }^{1,3}$ and up to $15 \%$ of users will become dependent. ${ }^{2,4}$ During periods of abstinence, milder cognitive and psychomotor impairments can persist for weeks in heavy users (average 11 joints per day for 10 years), ${ }^{5}$ similar to the extended withdrawal effects seen following the chronic use of other substances. ${ }^{6,7}$ Neurobiological differences in brain structure, ${ }^{8}$ connectivity, ${ }^{9}$ and function ${ }^{10}$ have been tentatively identified, though some morphological differences, at least, might reflect pre-existing traits. ${ }^{8}$ There is good evidence that cannabis has clinical efficacy for nausea, certain types of pain, and symptoms of multiple sclerosis, ${ }^{11}$ but most other proposed indications are largely based on anecdotes, putting physicians in a difficult position (i.e., being asked to prescribe cannabis for conditions where the evidence remains poor). Among the greatest concerns are that cannabis use increases the risk for car accidents ${ }^{12}$ and accelerates the onset of - perhaps even precipitates - schizophrenia. ${ }^{13}$

Most of the above effects are well supported, refuting suggestions that cannabis use is safe. Thus, the next question is, how big are these risks? The risk for car accidents is roughly doubled with cannabis use compared with the near 10-fold increase associated with alcohol intoxication. ${ }^{12}$ High-potency cannabis use is associated with a greater risk of schizophrenia, ${ }^{13}$ but the magnitude of this effect is small; ${ }^{14}$ indeed, it has been estimated that it would be necessary to prevent 9000 people from using cannabis to prevent 1 case of schizophrenia. ${ }^{15}$ The real effect might be even smaller. Recent evidence raises the possibility that the reported associations with psychosis reflect, in substantial part, effects of tobacco rather than cannabis. ${ }^{16}$ For overall risks, the most comprehensive analysis to date ranks marijuana eighth out of 20 substances, producing more personal and societal problems than MDMA, anabolic steroids, ketamine, and various hallucinogenic drugs, but fewer problems than alcohol, tobacco, heroin, crack, cocaine, and amphetamines. The largest contributors to cannabis's total score ( $28 \%$ of alcohol's score) are economic costs and burden on the criminal justice system. ${ }^{17}$

\section{Cannabis use and the law}

Criminalization too produces problems. ${ }^{18}$ Most prominently, an estimated $10 \%$ of users are arrested at one point in their lives. ${ }^{19}$ Here in Canada, 60000 people are arrested each year for possession, ${ }^{20}$ affecting employment opportunities, social stigma, and the ability to travel across borders. There is evidence that these laws are enforced disproportionately against certain minority groups. ${ }^{21}$ Economic analyses identify high financial costs from lost taxes and from charging, prosecuting, and imprisoning buyers and sellers. ${ }^{17,22,23}$

Despite these risks, cannabis use has become widely accepted in Canada. In 2015, 68\% supported a relaxing of regulations. ${ }^{24}$ About $20 \%-26 \%$ of Canadians between the ages of 15 and 25 years used cannabis at least once in the past year, ${ }^{25}$ and lifetime use for all Canadians is more than $40 \% .{ }^{20}$ Similar changes are occurring in the United States, and past year prevalence more than doubled from 2001-2002 to 2012-2013 (4.1\% v. 9.5\%). ${ }^{26}$ Regional analyses showed that the rates are not increasing uniquely in those states where legalization has been instituted, suggesting that the changes are not driven solely by the revised legal status. ${ }^{27,28}$ Cannabis use disorders increased in these regions also, but less steeply than rates of use. ${ }^{26}$

Does cannabis legalization increase the likelihood of children using cannabis? There is little evidence of this. In the current environment, youth have ready access to cannabis sellers, no ID required. Legalization would provide no guarantee that cannabis use will be restricted to adults. Indeed, alcohol and tobacco use commonly begin before the legal age limits. Compelling evidence that legalization lowers the age at which cannabis use begins, though, is lacking. ${ }^{19}$

\section{Definitions}

Depenalization: Decrease in the penalties for cannabis use. Decriminalization: Changing cannabis use from a criminal to a civil offense.

Legalization: Removal of punitive sanctions for cannabis use. Tetrahydrocannabinol (THC): Thought to be the primary psychoactive agent in cannabis.

Cannabidiol (CBD): A cannabis compound without psychoactive properties, but it might antagonize THC-induced anxiogenic effects and cognitive distortions. The relative ratio of $\mathrm{THC}$ to $\mathrm{CBD}$ has been proposed to influence the subjective effects of ingesting particular cannabis strains.

Correspondence to: M. Leyton, Department of Psychiatry, McGill University, 1033 Pine Avenue West, Montreal, Quebec, Canada; marco.leyton@mcgill.ca. 


\section{How might we think about the risks associated with cannabis use?}

The fact that cannabis use has risks does not necessarily mean that it needs to be criminalized. If it did, we would outlaw alcohol, automobiles, and bathtubs. Given this, how else might we think about the risks? Are they analogous to the dangers of using a poorly designed car or a dangerous activity, such as downhill skiing? If the former, we tend to be extremely intolerant. Product flaws that raise the risk of death by only a few per million are sufficient to elicit much public outcry (e.g., 2009-2011 Toyota vehicle recalls). ${ }^{29}$ If the latter, people tend to be more tolerant, accepting that they are choosing to participate in an activity with risks. Perhaps more pointedly, most people dislike risks imposed on them but are more accepting of ones that they have chosen. This raises the possibility that people will sue government-sanctioned sellers if they market a cannabis product with features different from advertised, but not if it is described accurately.

If cannabis products are legalized, the weight of evidence suggests that they should be controlled: product purity should be tested, tetrahydrocannabinol (THC) and cannabidiol (CBD) content accurately measured and labelled, and sales restricted to licensed dealers in specific locations. ${ }^{25}$ Developing the infrastructure to institute and coordinate these activities requires time and thought, but the empirical data from areas where legalization has been implemented indicate that it can be done. ${ }^{19,25}$ On balance, the experiences of countries that have legalized cannabis have been positive. The Dutch do not have elevated rates of cannabis use compared with neighbouring European countries. In Portugal, where use of all drugs has been decriminalized, drugrelated harms have diminished, and adolescent drug use has decreased. ${ }^{19,20}$ While the particulars of the Portuguese experiment might not transfer well to Canada, the weight of evidence from around the world suggests that potential costs of legalizing cannabis are outweighed by the benefits.

Acknowledgements: The author thanks Sherry Stewart for feedback on an earlier version of this editorial.

Affiliations: From the Department of Psychiatry, McGill University; the Department of Psychology, McGill University; the Department of Neurology \& Neurosurgery, Montreal Neurological Institute, McGill University; the Center for Studies in Behavioral Neurobiology, Concordia University; and the Research Unit on Children's Psychosocial Maladjustment, Université de Montréal; Montreal, Que., Canada.

Competing interests: M. Leyton declares having received operating funds through his institution from GlaxoSmithKline in 2006-2007 to conduct a study on naltrexone.

\section{References}

1. Silins E, Horwood LJ, Patton GC, et al.; Cannabis Cohorts Research Consortium. Young adult sequelae of adolescent cannabis use: an integrative analysis. Lancet Psychiatry 2014;1:286-93.

2. George TP, Vaccarino F. The effects of cannabis use during adolescence. Canadian Centre on Substance Abuse; 2015. Available: www.ccsa .ca/Resource\%20Library/CCSA-Effects-of-Cannabis-Use-during -Adolescence-Report-2015-en.pdf (accessed 2015 June 9).

3. Meier MH, Caspi A, Ambler A, et al. Persistent cannabis users show neuropsychological decline from childhood to midlife. Proc Natl Acad Sci U S A 2012;109:E2657-64.

4. Anthony JC. The epidemiology of cannabis dependence. In: Roffman RA \& Stephens RS (eds.), Cannabis dependence: its nature, consequences and treatment. Cambridge (UK): Cambridge University Press; 2006, pp. 58-105.
5. Bosker WM, Karschner EL, Lee D, et al. Psychomotor function in chronic daily cannabis smokers during sustained abstinence. PLoS ONE 2013;8:e53127.

6. Kosten TR, O'Connor PG. Management of drug and alcohol withdrawal. N Engl J Med 2003;348:1786-95.

7. Hughes JR. Effects of abstinence from tobacco: valid symptoms and time course. Nicotine Tob Res 2007;9:315-27.

8. Pagliaccio D, Barch DM, Bogdan R, et al. Shared predisposition in the association between cannabis use and subcortical brain structure. JAMA Psychiatry 2015;72:994-1001.

9. Zalesky A, Solowij N, Yücel M, et al. Effect of long-term cannabis use on axonal fibre connectivity. Brain 2012;135:2245-55.

10. Bloomfield MAP, Morgan CJA, Egerton A, et al. Dopaminergic function in cannabis users and its relationship to cannabis-induced psychotic symptoms. Biol Psychiatry 2014;75:470-8.

11. Hill KP. Medical marijuana for treatment of chronic pain and other medical and psychiatric problems: a clinical review. JAMA 2015;313:2474-83.

12. Hall $\mathrm{W}$. What has research over the past two decades revealed about the adverse health effects of recreational cannabis use? Addiction 2015;110:19-35.

13. Di Forti M, Marconi A, Carra E, et al. Proportion of patients in south London with first-episode psychosis attributable to use of high potency cannabis: a case-control study. Lancet Psychiatry 2015; 2:233-8.

14. Gage SH, Zammit S, Hickman M. Stronger evidence is needed before accepting that cannabis plays an important role in the aetiology of schizophrenia in the population. F1000 Med Rep 2013;5:2.

15. Hickman M, Vickerman P, Macleod J, et al. If cannabis caused schizophrenia - How many cannabis users may need to be prevented in order to prevent one case of schizophrenia? England and Wales calculations. Addiction 2009;104:1856-61.

16. Gage SH, Hickman M, Heron J, et al. Associations of cannabis and cigarette use with psychotic experiences at age 18: findings from the Avon Longitudinal Study of Parents and Children. Psychol Med 2014;44:3435-44.

17. Nutt DJ, King LA, Phillips LD, et al. Drug harms in the UK: a multicriteria decision analysis. Lancet 2010;736:1558-65.

18. Pryce S. Fixing drugs: the politics of drug prohibition. UK: Palgrave Macmillan; 2012.

19. Room R, Fischer B, Hall W, et al. Cannabis policy: moving beyond the stalemate. Oxford (UK); Oxford University Press \& The Beckley Foundation; 2010

20. Centre for Addiction and Mental Health. Cannabis policy framework; 2014. Available: www.camh.ca/en/hospital/about_camh/influencing _public_policy/Documents/CAMHCannabisPolicyFramework.pdf (accessed 2015 Oct. 7 ).

21. Khenti A. The Canadian war on drugs: structural violence and unequal treatment of black Canadians. Int J Drug Policy 2014;25:190-5.

22. Werb D, Nosyk B, Kerr T, et al. Estimating the economic value of British Columbia's domestic cannabis market: implications for provincial public policy. Int J Drug Policy 2012;23:436-41.

23. Ogrodnik M, Kopp P, Bongaerts X, et al. An economic analysis of different cannabis decriminalization scenarios. Psychiatr Danub 2015;27(Suppl 1):S309-14.

24. Support for marijuana legalization steady at more than half. In: Forum Research [website]; 2015 Available: http://poll.forumresearch .com/post/1362/just-one-tenth-think-current-laws-are-appropriate/ (accessed 2015 Sept. 20).

25. Canadian Centre on Substance Abuse (CCSA). Cannabis regulation: lessons learned in Colorado and Washington State. Ottawa (ON): CCSA; 2015. Available: www.ccsa.ca/Resource\%20Library/CCSA -Cannabis-Regulation-Lessons-Learned-Report-2015-en.pdf (accessed 2015 Nov. 13).

26. Hasin DS, Saha TD, Kerridge BT, et al. Prevalence of marijuana use disorders in the United States between 2001-2002 and 2012-2013. JAMA Psychiatry 2015;72:1235-42.

27. Hall W, Weier M. Assessing the public health impacts of legalizing recreational cannabis use in the USA. Clin Pharmacol Ther 2015;97:607-15.

28. Canadian Centre on Substance Abuse (CCSA). Marijuana for NonTherapeutic Purposes. Ottawa (ON): CCSA; 2014. Available: www .ccsa.ca/Resource\%20Library/CCSA-Non-Therapeutic-Marijuana -Policy-Brief-2014-en.pdf (accessed 2015 Oct. 21).

29. 2009-11 Toyota vehicle recalls. In: Wikipedia [website]. Available: https:/ / en.wikipedia.org/wiki/2009-11_Toyota_vehicle_recalls (accessed 2015 Sept. 20). 